während das Citronmethylat des Kalks sich sehr in letzterer Flussigkeil löst.

Alle ätherisirten Säuren bilden sich durch den directen Einfluss der primitiven Säuren auf Alkohol oder Holzgeist sehr leicht. Den Erfahrungen Antois' zufolge ist gedachte Methode auch vortheilhaft, um die analogen Verbindungen der Oxalsäure hervorzubringen.

A mide. Die neutralen Aether führen unmittelbar zu den Amiden. Eine geregelte Wirkung des ammoniakalischen Alkohols auf den Weinsteinsäureäther liefert die Tartramethone oder den tartramidischen Aether, welcher mit Sorgfalt durch Alkalien entmischt, die in Wasser und Alkohol sehr lösliche tartramidische Säure darbietel. Lässt man hier Ammoniak dauernd fortwirken, so verändert es die Tartramethone in Tartramid. Setzt man jenes Reagens mit Citronäther in Berührung, so entsteht - die Bildung intermediärer, aber unvollkommen isolirbarer Producte nicht zu gedenken - Citramid als ein stabiles Erzeugniss in den Reihen des Alkohols und des Holzgeistes. Endlich der Aepfelsäureäther unter den ebengedachten Umständen, das Melamid, dessen Zusammensetzung der des Asparagins gleichkommt. Mehrere Kennzeichen, die diesen beiden Körpern eigen sind, scheinen eine Identität unter denselben zu rechtfertigen, die jedoch erst durch grïndliche Forschungen Gewissheit erlangen könnte. Diese drei Amide sind wenig löslich in kaltem Wasser; sie bieten regelmässige Krystalle dar. Die Aether und Amide der Weinstein- nnd Aepfelsäure wirken auf das polarisirte Licht. Dits Tartramid besitzl diese Eigenschaft in einem merkwürdigen Grade.

Alle in diesem Aufsatze angefuhrten Körper sind analysirt. Ihre Zusammensetzung entspricht der analoger Körper; es war daher leicht, sie nach den zahlreichen bekannten Beispielen vorherzusehen. (Journ. de Pharm et de Chim. Dec. 1852. p. 407.) du Mênil.

\title{
Ermittelung der Verfälschung des Zuckersyrups mit Stärkesyrup.
}

Soubeiran hat seinen friheren Versuchen uber die Verfälschung des Zuckersyrups mil Stärkesyrup einige bemerkenswerthe Thatsachen hinzugefügt. Er sagt unter Anderm : Man erkennt ein Gemenge von Stärke- und Zuckersyrup mittelst folgender Probe. Wird ein mit kaustischem Kali versetzter Syrup in's Sieden gebrachl, so enthält er, wenn er sich schwärzt und nach Caramel riecht, Stärkesyrup. 
Verdünnt man solchen Syrup mil einem gleichen Volum Wasser und mischt man demselben etwas jodirtes Kaliumjodid hinzu, so wird die Flüssigkeit roth. Diese Reaction ist sehr empfindlich. Ein Fünfzigstel Stärkesyrup ist auf diese Weise noch abzuschätzen. Kleinere Portionen desselben werden entdeckt, wenn man neben dem zu prifenden Syrup ein Glas mit gleichem Volum Wasser stellt, beiden gleiche Quantität des Reagens hinzumischt und eben die entstandenen Farbenniancen vergleicht. Ein mit Stärkemehlsyrup verfälschter Zuckersyrup wird mit mehrmals seinem Volum Weingeist milchicht und trübe, es setzl sich nach einiger Zeit eine syrupartige, undurchsichtige, dickliche Masse ab. Man darf sich also bei dieser Probe nicht übereilen; auf jeden Fall ist es sicher, das jodirte Kaliumjodid anzuwenden und die rothe, vom Dextrin herruhrende Färbung abzuwarten, denn wo sich diese zeigt, bat auch eine Verfalschung statt gefunden. Die Starke des Handels enthält immer Dextrin. (Journ. de Pharm. el de Chim. Dec. 185l. p.402.) du Mênil.

\section{Wirkung des Zinkchlorids auf das Amylum.}

Barreswil und Rillet haben durch Versuche bewiesen, dass Zinkchlorid die Eigenschaft - gleich der Schwefelsäure - hat, den Alkohol zu ätherisiren und Amylum in Zucker umzuändern. Setzt man zartes Filtrirpapier mit einer concentrirten Auflösung des Zinkchlorids in Beruhrung, so quillt dieses auf und löst sich. Die Flüssigkeit bleibt klar. Das so gelöste Papier verwandelt sich durch längere Einwirkung des Chlorids gänzlich in Zucker, welcher dann eine fernere Umänderung erleidet. Wie es auch mittelst der Schwefelsäure geschieht, geht der Zuckerbildung eine Modification der behandelten Substanz vorher. Das Papier färbt sich, durch das Zinkchlorid gesättigt, blau (mit Jod?). Kaustisches Kali und Natron haben bekanntlich eine der des Zinkchlorids ähnliche Wirkung auf Papier und Cellulose. (Journ. de Pharm. et de Chim. Mars 1852. p. 205.) du Mênil.

\section{Vergleichende Versuche über Ratanhia- und Tormentillwurzel.}

Dause d. ä., Pharmaceut zu Paris, ist durch mehrere Versuche zu der Ueberzeugung gelangt, dass die Wurzel der Tormentilla die der Hatanhia vôllig ersetzen kann. 